\title{
MUSEU, PATRIMÔNIO E CIDADE: camadas de sentido em Paraty
}

Mario Chagas $^{1}$ e Claudia Storino ${ }^{2}$

\section{A Musa das Ruas}

A Musa das ruas é a Musa que viceja nos becos e rebenta nas praças, entre o barulho da populaça e a ânsia de todas as nevroses, é a Musa igualitária, é a Musa-povo, que desfaz os fatos mais graves em lundus e cançonetas, é a única sem pretensões porque se renova como a própria vida. Se o Brasil é a terra da poesia, a sua grande cidade é o armazém, o ferro-velho, a aduana, o belchior, o grande empório das formas poéticas.

João do Rio

${ }^{1}$ Poeta, museólogo, doutor em Ciências Sociais, professor da Universidade Federal do Estado do Rio de Janeiro (UNIRIO), com atuação no Programa de Pós-graduação em Memória Social, no Programa de Pós-graduação em Museologia e Patrimônio e na Escola de Museologia. Professor convidado da UFBA e da ULHT, em Lisboa. Assessor cultural do Museu da República/Ibram.

${ }^{2}$ Especialista em Conservação e Restauração de Bens Culturais e Mestre em Memória Social pelo Programa de Pós-graduação em Memória Social (PPGMS) da Universidade Federal do Estado do Rio de Janeiro (UNIRIO). Arquiteta do Instituto do Patrimônio Histórico e Artístico Nacional e diretora do Sítio Roberto Burle Marx/Iphan. 


\section{Resumo:}

O papel dos museus nas estratégias de preservação das cidades históricas incluídas na categoria de patrimônio constitui o eixo condutor do presente texto que, por sua vez, reconhece que essas cidades são, elas mesmas e em um só tempo, assim como os museus, lugares de memória e de esquecimento, de poder e de resistência.

Os museus aqui são compreendidos como práticas sociais, antros de relação e dispositivos de narração que se constroem por meio de espacialidades, temporalidades, imagens, informações, vivências e convivências tratadas, em simultâneo, como bens, representações e manifestações culturais.

O estudo concentra-se em um museu situado em uma cidadepatrimônio, o Museu de Arte Sacra ${ }^{3}$ da cidade de Paraty.

Palavras-have: preservação; museus; patrimonio; Patrimonio urbanistico

\section{Abstract:}

The role of museums in strategies for preservation of historic cities included in the category of heritage is the guiding thread of this text which, on the other hand, recognizes that these cities are themselves and one time, as well as

\footnotetext{
${ }^{3}$ Registre-se desde agora que o conceito de arte sacra necessita de urgente revisão. No mundo contemporâneo, a manutenção de um conceito contrário à diversidade cultural, que considera como arte sacra a arte produzida no âmbito de apenas uma experiência religiosa, não colabora para o espírito de respeito às diferenças e tende a produzir discriminação e preconceito em relação a outras religiões e suas correspondentes experiências e práticas poéticas. Ainda assim, o Museu de Paraty guarda surpreendentes possibilidades de conexão com as experiências universais de religiosidade.
} 
museums, places of memory and forgetting, power and resistance.

The museums here are understood as social practices, havens for relationship and storytelling devices that are constructed through spatiality, temporality, images, information, experiences and cohabitation handled simultaneously as goods, representations and cultural events.

The study focuses on a museum located in a city-heritage, the Museum of Sacred Art in the city of Paraty.

Keywords: conservation; museums; heritage; urban heritage

\section{As cidades e o desejo}

No centro de Fedora, metrópole de pedra cinzenta, há um palácio de metal com uma esfera de vidro em cada cômodo. Dentro de cada esfera, vê-se uma cidade azul que é o modelo para uma outra Fedora. São as formas que a cidade teria podido tomar se, por uma razão ou outra, não tivesse se tornado o que é atualmente. Em todas as épocas, alguém, vendo Fedora tal como era, havia imaginado um modo de transformá-la na cidade ideal, mas, enquanto construía seu modelo em miniatura, Fedora já não era mais a mesma de antes e o que até ontem havia sido um possível futuro hoje não passava de um brinquedo numa esfera de vidro.

Agora Fedora transformou o palácio das esferas em museu: os habitantes o visitam, escolhem a cidade que corresponde aos seus desejos, contemplam-na imaginando-se refletidos no aquário de medusas que deveria conter as águas do canal (se não tivesse sido dessecado), percorrendo no alto baldaquino a avenida reservada aos elefantes (agora banidos da cidade), deslizando pela espiral do minarete em forma de caracol (que perdeu a base sobre a qual se erguia).

No Atlas do seu império, ó Grande Khan, devem constar tanto a Fedora de pedra quanto as pequenas Fedoras das esferas de vidro. Não porque sejam 
igualmente reais, mas porque são todas supostas. Uma reúne o que é considerado necessário, mas ainda não o é; as outras, o que se imagina possível e um minuto mais tarde deixa de sê-lo.

Ítalo Calvino

O papel dos museus nas estratégias de preservação das cidades históricas incluídas na categoria de patrimônio constitui o eixo condutor do presente texto que, por sua vez, reconhece que essas cidades são, elas mesmas e em um só tempo, assim como os museus, lugares de memória e de esquecimento, de poder e de resistência.

Os museus aqui são compreendidos como práticas sociais, antros de relação e dispositivos de narração que se constroem por meio de espacialidades, temporalidades, imagens, informações, vivências e convivências tratadas, em simultâneo, como bens, representações e manifestações culturais.

O estudo concentra-se em um museu situado em uma cidade-patrimônio, o Museu de Arte Sacra ${ }^{4}$ da cidade de Paraty. Interessa investigar as relações entre o museu e o núcleo urbano, compreendendo que eles partilham características singulares e trajetórias interligadas e que as suas relações resultam de condições históricas e geográficas, de configurações sociais e práticas específicas.

\section{A cidade histórica como artefato e mentefato}

${ }^{4}$ Registre-se desde agora que o conceito de arte sacra necessita de urgente revisão. No mundo contemporâneo, a manutenção de um conceito contrário à diversidade cultural, que considera como arte sacra a arte produzida no âmbito de apenas uma experiência religiosa, não colabora para o espírito de respeito às diferenças e tende a produzir discriminação e preconceito em relação a outras religiões e suas correspondentes experiências e práticas poéticas. Ainda assim, o Museu de Paraty guarda surpreendentes possibilidades de conexão com as experiências universais de religiosidade. 
Compreendendo a cultura como "a estrutura de significados por meio dos quais o homem confere forma à sua experiência", tal como propõe Clifford Geertz (1966), o conceito de artefato, como tradução dessa estrutura de significados, aplica-se a tudo aquilo que, no mundo material, é criado ou modificado pela intervenção humana (RAPOPORT, 1983, p.178). Essa definição abrange os componentes da paisagem resultantes de tais ações, inclusive os aglomerados humanos, sejam eles aldeias, pequenas cidades ou grandes metrópoles. Em qualquer cultura os artefatos são utilizados para organizar relações sociais por meio de formas e de comunicação não verbal, atuando como indicativos sociais e como ordenadores da comunicação entre indivíduos.

Sob o ponto de vista de sua representação simbólica, ou seja, considerada como artefato, a cidade possui a dualidade estrutural presente nos objetos museológicos a que se refere José Reginaldo Santos Gonçalves: "uma dimensão contingente e perecível, como objetos materiais, e uma dimensão abstrata e transcendente, como representações de ideais e valores sociais" (GONÇALVES, 2003).

As configurações espaciais da cidade refletem as sucessivas materializações de poder, de modos de ser e estar no mundo, formando um panorama carregado de tensões e disputas, de memória e de esquecimento.

O espaço da cidade é o espaço vivido, instituído a partir das maneiras pelas quais as sociedades o utilizam, e como tal possui uma dinâmica própria, em permanente transformação, assim como constantemente se atualizam as relações sociais e simbólicas dos sujeitos que sobre ele atuam. Nesse espaço, a distinção entre material e imaterial não viceja: o que dá sentido à pedra do calçamento do beco ou ao monumento da praça está na ordem do encontro entre o material e o imaterial; são camadas de valores, significados 
e funções, são acúmulos de experiências de sentido e de percepções espaciais e temporais.

Por essa viela, é possível compreender que as cidades não são apenas concretudes, materialidades e corporeidades; elas também são vida, movimento e devir; são incorpóreos, imaterialidades e espiritualidades; são "mito em carne viva", mentefatos ${ }^{6}$ imbricados com artefatos e "grandes empórios das formas poéticas" (RIO, 1997).

Um dos desafios dos museus contemporâneos é o da manutenção de um diálogo criativo, tanto do ponto vista social, quanto ambiental e histórico, com o meio em que estão inseridos. Esse desafio, no que se refere aos museus instalados em cidades-patrimônio, exige que eles se assumam como processos permeáveis e orgânicos, que estejam atentos ao alargamento da noção de patrimônio e que lidem com a cidade como um artefato-mentefato passível de ser submetido a um processo de musealização diferenciado, que compreenda e respeite os diferentes ritmos e tempos da cidade, os seus diferentes usos e percursos, os seus diferentes cidadãos, em síntese: a sua "alma"7 e a dinâmica da vida social urbana.

${ }^{5}$ Ver o poema de João Cabral de Mello Neto, publicado no livro Museu de Tudo e depois. Rio de Janeiro: Nova Fronteira, 1988. Ver também o site:

http://revistas.ulusofona.pt/index.php/cadernosociomuseologia/art icle/viewFile/366/275.

${ }^{6}$ Neologismo utilizado por Ubiratan D' Ambrósio em sua obra "Da realidade à ação: reflexões sobre a Educação (e) Matemática", 1988, com o objetivo de referir-se aos fatos ou produções mentais, incluindo aí as manifestações afetivas e cognitivas, passando pelo sistema de valores, pelos saberes e fazeres, pelas religiões, pelas filosofias, ideologias e ciências, em síntese pela denominada "vida social".

${ }^{7}$ Ver o livro A alma encantadora das ruas, de João do Rio, contendo textos publicados na imprensa carioca entre 1904 e 1907. Org. Raúl Antelo. São Paulo: Companhia das Letras, 1997. 


\section{Paraty: cidade histórica}

Como toda cidade, Paraty é um objeto complexo que contém e articula várias categorias patrimoniais: é lugar de memória, de esquecimento, de poder e de resistência, é repertório acumulado, documento e monumento histórico e artístico $^{8}$. Além disso, Paraty mantém vivas muitas tradições, festas, saberes e modos de produção centenários, expressões do denominado patrimônio imaterial.

A pequena cidade costeira de Paraty situa-se na Costa Verde, litoral sul do Estado do Rio de Janeiro, a $236 \mathrm{~km}$ da cidade do Rio de Janeiro e a 330 km da cidade de São Paulo; portanto, a meio caminho das duas cidades mais populosas do país.

Paraty originou-se num pequeno núcleo erguido no início do século XVII por indivíduos vindos da Capitania de São Vicente pelo caminho dos índios Guaianás, primeiros ocupantes da região. Ergueram ali uma ermida, que dedicaram a São Roque, em torno da qual o primeiro núcleo urbano se instalou.

A conformação física do ambiente natural e a situação geográfica da pequena povoação, naquele ponto de inflexão da costa, ao pé do caminho que transpunha a serra e à beira de uma enseada relativamente tranquila determinaram sua vocação: Paraty rapidamente viria a se constituir em ponto estratégico nas rotas de comércio da região, um trajeto que seguia por mar do Rio de Janeiro até

\footnotetext{
${ }^{8}$ Ver a dissertação de Márcia Sant Anna, denominada "Da Cidade Monumento à Cidade Documento - Trajetória de uma norma de preservação de áreas urbanas no Brasil (1937-1990)", defendida na Faculdade de Arquitetura e Urbanismo da Universidade Federal da Bahia, em 1995.
} 
Paraty e, daí em diante transpunha, por uma estrada íngreme e perigosa, a Serra do Facão.

$\mathrm{Na}$ história do município de Paraty, os momentos ligados aos ciclos econômicos do ouro e do café destacam-se pelo grande impulso conferido ao desenvolvimento da vila. Foram períodos de prosperidade, que possibilitaram aos paratienses investir na construção e na reforma dos edifícios religiosos e das casas de comércio e moradia, bem como no aprimoramento dos equipamentos urbanos.

O ciclo do café constituiu o último impulso de prosperidade e modernização da cidade, antes do longo período de isolamento que viria a seguir.

A partir de 1850 começam a ser instaladas no Brasil as primeiras ferrovias e com elas surgiu um caminho mais eficiente para o escoamento da produção cafeeira do Vale do Paraíba ao porto do Rio de Janeiro. Mangaratiba, Paraty e Ubatuba começaram a perder sua importância como portos de escoamento da produção e porta de entrada para bens manufaturados.

Com a abolição da escravatura, em 1888, os engenhos de açúcar e as fazendas de café entraram em declínio. A transição entre os séculos XIX e XX foi marcada pela decadência da cafeicultura na região do Vale do Paraíba e a estagnação dos antigos portos coloniais. Paraty permanecia com uma configuração de vila colonial, servida por meios de transporte antiquados, carente de instalações de esgoto, água e energia.

Sobreveio um período de praticamente um século de isolamento. Paraty tornou-se um local de difícil acesso, em comparação com o restante do país. Com o comércio decadente e a comunicação cortada, a cidade voltou-se para si mesma e apegou-se ao que havia restado: uma vida social restrita ao grupo local de habitantes, organizada em torno da sucessão cíclica das festas religiosas preparadas pelas irmandades. 
As conjunturas formadoras da comunidade Paratiense parecem ter favorecido o desenvolvimento de uma mentalidade social ao mesmo tempo autossuficiente e conservadora, cujos traços principais persistem até os dias de hoje, assim como persistem as festas, o traçado urbano e as formas arquitetônicas. Marina Mello e Souza observa que a vida da cidade se desenvolvia de forma bastante independente da administração pública do país:

"Tanto as atividades ligadas aos negócios e à produção, quanto as ligadas à vida religiosa, eram financiadas pelos próprios moradores, que ao lado dos impostos sobre as atividades comerciais ainda mantinham os caminhos, as igrejas e os padres." (SOUZA, 1994).

Da mesma forma que na maioria das cidades do país, a religião desempenhava na estruturação da sociedade paratiense um papel de destaque. Havia no século XIX mais de uma dúzia de irmandades religiosas, e praticamente todas as pessoas eram filiadas a alguma delas. Essas irmandades refletiam a estratificação da sociedade e as distinções raciais e de gênero (a maior parte era composta por homens brancos, ainda que houvesse irmandades de negros e de pardos, e algumas de mulheres) e, além da manutenção de seus templos e realização de festas e celebrações litúrgicas, desempenhavam papéis assistenciais e estruturais na sociedade.

O Serviço do Patrimônio Histórico e Artístico Nacional $(\text { SPHAN) })^{9}$ começou a atuar em Paraty na década de 1940. Em

\footnotetext{
${ }^{9}$ Em 1990, durante o governo de Fernando Collor de Mello, a então Secretaria do Patrimônio Histórico e Artístico Nacional, juntamente com a Fundação Nacional Pró-Memória (FNPM), foram extintas. Esses dois órgãos deram origem ao Instituto Brasileiro do Patrimônio Cultural (IBPC). Em 1994, o IBPC foi renomeado e passou a denominar-se Instituto do Patrimônio Histórico e Artístico Nacional (IPHAN).
} 
1945, a cidade foi decretada Monumento Estadual, por iniciativa do interventor Ernani do Amaral Peixoto, de origem paratiense. Ainda nessa época, a comunicação com o Rio de Janeiro se dava por via marítima, mediante uma viagem que se fazia em dias alternados, passando por Angra dos Reis e Mangaratiba. Durante muito tempo esta foi a única ligação de Paraty com o restante do país.

Em meados da década de 1950 foi aberta uma estrada paralela à antiga estrada da Serra do Facão, religando Paraty à cidade de Cunha. Ainda que fosse um acesso precário, a abertura dessa estrada propiciou a "redescoberta" de Paraty por artistas e determinados segmentos da classe média alta, interessados em lugares pitorescos, isolados e sossegados pelos mais diferentes motivos, inclusive para ocupar o tempo de lazer.

Em 1958, o Instituto do Patrimônio Histórico e Artístico Nacional inscreveu o conjunto arquitetônico e paisagístico da cidade de Paraty no Livro do Tombo das Belas Artes e no Livro do Tombo Arqueológico, Etnográfico e Paisagístico. Em 1974, a Rodovia Rio-Santos foi concluída e nesse mesmo ano o tombamento federal foi estendido a todo o município. A abertura da Rodovia e o tombamento pelo IPHAN impulsionaram o turismo e, com isso, novo ciclo de desenvolvimento econômico e grandes mudanças sociais afetaram a cidade.

Durante a abertura da Rodovia Rio-Santos, ou seja, na década de 1960, um fato em especial abalou a sociedade Paratiense. As irmandades religiosas, que durante os séculos XVIII e XIX haviam constituído em Paraty o centro do poder tanto público, quanto religioso - foram extintas, ao que tudo indica, em função de uma disputa com o clero. Com o apoio do bispo, o pároco local dissolveu autoritariamente todas as irmandades Paratienses e reuniu sob a custódia da paróquia, na igreja matriz, seus bens patrimoniais móveis, inclusive todos os objetos considerados sagrados e utilizados nas 
festas. Essa atitude adquiriu a dimensão de uma cisão traumática, de um saque cultural e patrimonial contra a comunidade local. Contudo, as tradições, as celebrações e as festas resistiram e não deixaram de ser realizadas pela população. O poder clerical se empenhava na produção de esquecimento, dissolvia organizações, sequestrava objetos sagrados e em nome de outro sagrado, vandalizava e profanava o sagrado; a comunidade acionava os dispositivos de memória a favor da resistência, da potência criativa e criadora.

O Museu de Arte Sacra de Paraty, criado na década de 1970 por meio de convênio firmado entre a Diocese de Barra do Piraí - Volta Redonda e o Instituto do Patrimônio Histórico e Artístico Nacional, foi instalado na Igreja de Santa Rita de Cássia, que estava em desuso, em péssimo estado de conservação e que foi restaurada pelo IPHAN no período de 1967 a 1976. Desde o início o museu teve um papel de destaque na valorização da comunidade local.

\section{Paraty: museu e patrimônio}

Há em boa parte da população de Paraty um catolicismo popular estreitamente imbricado com os aspectos pagãos das festividades, crenças e práticas cotidianas. É sabido que no processo de colonização do Brasil o papel da religião foi marcante e em muitos aspectos dominador, disciplinador e controlador.

A religião católica teve uma presença notável, para o bem e para o mal, no Estado e na vida social brasileira até as primeiras décadas do século XX; nas décadas seguintes, especialmente após o Movimento da Escola Nova e da Revolução de 1930, a sua imbricação com o Estado e o seu papel social foram sendo cada vez mais criticados e 
reduzidos $^{10}$. Paraty, contudo, devido aos acontecimentos que marcaram sua trajetória histórica e propiciaram sua singularidade, não viveu essa transformação no mesmo ritmo de outras cidades brasileiras e, por esses mesmos motivos, desenvolveu uma relação muito particular com a religiosidade.

O patrimônio cultural de Paraty, como o de qualquer cidade, constitui um conjunto complexo, composto por uma multiplicidade de elementos de naturezas diversas, articulados uns com os outros de variadas maneiras e cada um de modo específico com o todo. Por motivos metodológicos e operacionais é possível organizar os elementos constituintes desse patrimônio em categorias, sabendo que a categorização não organiza e não ordena o mundo, mas a nossa visão sobre ele.

De uma maneira geral, o universo dos bens culturais (incluindo aí os denominados bens naturais) é subdividido em duas grandes categorias: bens materiais e bens imateriais; estas, por sua vez, se subdividem em outras categorias mais detalhadas e específicas.

Os Livros de Tombo e de Registro do IPHAN exemplificam esse processo de subdivisão: ao patrimônio material estão dedicados quatro Livros de Tombo: 1. Arqueológico, etnográfico e paisagístico; 2. Histórico; 3. das Belas Artes e 4. das Artes Aplicadas. Ao patrimônio imaterial correspondem quatro Livros de Registro: 1. dos Saberes; 2. das Celebrações; 3. das Formas de Expressão e 4. dos Lugares $^{11}$.

${ }^{10}$ É preciso relativizar essa última afirmação; o Estado brasileiro, mesmo nos tempos atuais, ainda não conseguiu assumir inteiramente a sua dimensão republicana e laica.

${ }^{11}$ Para maiores informações consultar: portal.iphan.gov.br/portal/montarPaginaSecao.do?id=12456\&retor $\underline{\text { no=paginalphan }}$. 
Para além das oficialidades, é preciso reconhecer que aquilo que cotidianamente dá sentido ao assim chamado patrimônio não está contido nas formas materiais, nem nas manifestações intangíveis, mas nos indivíduos que os produzem, reproduzem, alteram, transformam, vandalizam, conservam, utilizam e valorizam.

Nesse sentido, o patrimônio não é uma lista ou um rol, é uma prática social. No âmbito dessa prática é possível construir um debate que, ultrapassando os limites do privado e do público, esteja aberto para o reconhecimento da potência do comum (PIRES, 2014, p.51). O ar é um bem comum, a água é um bem comum, o fogo (e outras modalidades de energia) é um bem comum e a terra também é um bem comum, ainda que estejam sistematicamente ameaçados de privatização ou de ocupação pelo poder público em nome de interesses particulares; além disso, encontram-se também na categoria do comum, como exemplifica Vladimir Sibylla Pires, ideias, conhecimentos, linguagens, redes de comunicação, circuitos culturais, informações, códigos, afetos e relações (PIRES, 2014, p.5153). Esses comuns afetam a vida social e produzem impactos nas práticas e nos conceitos patrimoniais e abrem espaço para se pensar, por exemplo, a hipótese de um fratrimônio, ou de uma herança criativa, produzida e partilhada aqui e agora, insubmissa aos dispositivos de captura acionados pela lógica mercantilista. Em síntese: há uma herança comum que não está restrita a um rol qualquer, mas que, ao contrário, está aberta às novas percepções e compreensões patrimoniais.

As práticas de musealização e patrimonialização do Museu de Arte Sacra de Paraty envolvem a custódia de um acervo que pertenceu às irmandades, a circulação desse mesmo acervo pelas ruas de Paraty em determinadas festas, a transferência de sua custódia para os festeiros de cada ano 
e a radical flexibilização das noções de segurança e risco patrimonial.

Essas práticas levantam um conjunto novo de problemas para o campo museal e museológico, entre os quais se destacam: musealização temporária versus musealização permanente; musealização versus desmusealização; metamorfose sazonal entre o valor de culto e o valor de cultura ou entre o valor de culto e o valor de exposição (BENJAMIN, 1985, p.172-174); esgarçamento radical das fronteiras entre o material e o espiritual, o tangível e o intangível; rompimento com a noção de patrimônio público e de patrimônio privado e afirmação de um patrimônio comunitário ou comum.

Cesare Brandi, em sua teoria da restauração, identifica o momento fenomenológico da apreensão da obra de arte como ponto gerador de sua existência e indica que toda e qualquer obra só passa a ser arte ao ser reconhecida como tal, o que implica o entendimento de que não existe obra de arte no vazio (BRANDI, 1989, p.14-15). De igual modo, o denominado patrimônio cultural só se constitui como herança quando é reconhecido e aceito como tal. Esse reconhecimento, no entanto, não é dado, não é simples e não é óbvio, ele depende das relações dinâmicas tecidas entre os grupos humanos, das pelejas e disputas que se dão em torno dos lugares, dos objetos, dos conhecimentos e das práticas sociais que compõem uma teia de significados e que estruturam os modos de pensar, sentir e agir.

Em Paraty essa teia patrimonial é bastante perceptível, pois estão mantidos em uso e em transformação grande parte de seus elementos materiais e imateriais, bem como as relações entre eles. Dessa teia participam o Bairro Histórico, com suas feições mais ou menos alteradas desde o século XVIII, as festas religiosas que pontuam os ciclos do tempo e reforçam crenças e laços sociais, os modos de falar, as danças, a culinária, a paisagem cultural, o ambiente natural 
e também as relações entre os diversos grupos sociais que habitam a região, permeadas por acordos, conflitos e preconceitos, como no caso dos índios Guarani da Aldeia de Paraty-Mirim.

Entre a trama urbana e a urdidura das festas, o acervo do museu continua imerso na vida social Paratiense. É a "prata da casa", tesouro guardado com zelo através dos anos, propriedade de todos, bem comum que pernoita nas casas e passa de mão em mão carregado nas procissões, reconhecido nas ruas, valorizado nos cultos e na exposição do museu. Esse é um acervo que se mantém ainda ligado pelos fios de muitas relações com indivíduos, edifícios, crenças, festas, ruas, ladainhas, danças, barcos, montanha e mar. Essa coleção, nem pública nem privada, mas comunitária, mantém tradições e estabelece novas relações com a Paraty de hoje, com a televisão, o cinema, os turistas, os novos moradores, as crianças, a internet, as novas festas, os novos sons, as novas instituições.

E no que consiste esse grupo de objetos que haviam sido reunidos na matriz, por ocasião da extinção das irmandades, e que a partir da assinatura do convênio entre a Diocese de Barra do Piraí - Volta Redonda e o IPHAN, em agosto de 1976, passou a constituir o acervo do museu?

No Arquivo Central do Iphan-RJ há um documento que descreve o acervo do museu, no momento de sua criação ${ }^{12}$, totalizando 396 itens, entre os quais se incluem:

(1) objetos relacionados a cultos, festas e procissões crucifixos, imagens, oratórios, coroas, ostensórios, custódias, caldeiretas, navetas, turíbulos, cálices, colherinhas, abotoadeiras, pomba para bandeira do divino, pia batismal, andor, atributos e ornamentos de santos, apliques ornamentais, brincos, broches, correntinhas, escapulários,

${ }^{12}$ Ao longo do tempo esse acervo recebeu acréscimos e sofreu alterações, mas nada disso modificou de forma significativa a coleção inicial. 
diademas, báculo, cravos de prata, porcas, medalhão, pena, balança, flechas, chaves, cordões, rosários, cruz de cristo, relicários, pingentes, espada, bastões, varas de irmandade;

(2) documentos e registros das atividades das irmandades livros, manuscritos, fotografias;

(3) objetos de uso cotidiano dos templos - jarras, bacias, vasos, candelabros, castiçais, formas para fazer hóstia, caldeira, arandelas, mangas de vidro, pedras de altar, missais, estantes para missal, portas-missal, bancos de igreja, baús, espevitadeiras, rosácea, hastes, sinos, lampadários, lanternas, tocheiros, cintos, urna, relógios de parede.

É um acervo conhecido e apreciado pelo povo paratiense. Boa parte dos objetos transita pela cidade diversas vezes por ano, integrando as festas que proporcionam às ruas e às casas um sentido especial. $\mathrm{Na}$ maior festa religiosa da cidade, a do Divino Espírito Santo, que reúne anualmente milhares de pessoas, esse acervo tem papel de destaque; participa de procissões e celebrações, transfere-se para a casa dos festeiros durante os dez dias da festa e circula pelas ruas nas mãos de adultos e crianças.

Um momento especial da Festa do Divino é o almoço comum, preparado durante vários dias por voluntários da comunidade, na maioria senhoras. Dona Filhinha, organizadora do almoço, em entrevista concedida a Claudia Storino em maio de 2007, descreveu essa atividade nos seguintes termos:

“A gente faz comida para cinco mil pessoas. São 150 kg de feijão, $150 \mathrm{~kg}$ de arroz, $150 \mathrm{~kg}$ de macarrão. Boi, depende de quanto o festeiro ganha: este ano ele matou oito bois. Frango, já está na faixa dos 600 . (...) Somos umas quinze pessoas na cozinha, mas no fogão mesmo somos oito; mas tem as outras que picam a carne, que limpam, que fazem tempero, essa coisa toda, então, tem umas trinta pessoas. (...) Tudo isso que a senhora está vendo aí é ganho, o 
festeiro não gastou um tostão. O feijão é doado: a gente já tem a pessoa certa que doa. O arroz é doado: a gente já tem a pessoa certa que doa. 0 bacon, para fazer a farofa de feijão - que é a farofa famosa - o macarrão, tudo, tudo, tudo que a senhora pode imaginar que leva numa cozinha para fazer este almoço, foi doado. Não se gastou um tostão. E a gente faz isso: vai de casa em casa perguntando às pessoas o que é que pode dar, anota num caderno, terça e quarta nós saímos com o carro pegando as coisas, e ainda tem coisa que vão mandar. Ainda agora mandaram dez quilos de linguiça. (...) Pra você ter uma ideia, antigamente não tinha geladeira em Paraty, não tinha frango limpo, era tudo pegado do terreiro, a galinha do galinheiro. Era tudo muito mais difícil, eram porcos; boi, assim, não tinha...". (STORINO, 2008, p.160)

O almoço é servido no sábado, na praça principal da cidade, a todos os que comparecerem. Nessa ocasião comem juntos velhos, moços, crianças, brancos, negros, índios, autoridades, adeptos de qualquer religião. Esse almoço comunitário materializa a partilha, a dádiva, e rompe com a lógica mercantilista.

\section{Considerações finais}

Do ponto de vista diacrônico e sincrônico, a coleção do Museu de Arte Sacra de Paraty está conectada com a vida social; cada um dos seus objetos está investido de uma aura (BENJAMIN, 1984, p.165-196) e manifesta um mana (MAUSS, 1974); a coleção estabelece uma ligação incorpórea com o passado que habita o imaginário da cidade.

Nos tempos de isolamento, esses objetos ancoraram o sentido de dignidade social dos paratienses; extintas as irmandades, proporcionaram o suporte material para a 
continuidade das práticas tradicionais, cuja repetição cíclica realimentou, ao longo dos anos, o sentido de pertencimento e a coesão social. Posteriormente, essa coleção favoreceu a retomada de festas que permaneciam vivas na memória coletiva. A partir da década de 1970, além de atuar como elo entre o presente e o passado, esse acervo assumiu outros papéis: o de dispositivo de construção de narrativas museais e o de instrumento de resistência pela afirmação da distinção num momento em que, diante do impacto gerado pelo incremento do turismo, a comunidade se afirmava pela valorização das diferenças.

Como indicado, os objetos que circulam pelas ruas antigas, carregados por muitas mãos, saudados a partir das janelas enfeitadas, admirados e cultuados com alegria, constituem pontos de interseção entre a cidade e os cidadãos, elos entre o passado e o presente, as tradições e as inovações, as festas e o cotidiano. A compreensão da importância desse trânsito cíclico permite perceber que o lugar desses objetos é o museu e é a cidade; também são as relações, as narrativas, as festas, o afeto e o imaginário dos cidadãos. $\mathrm{O}$ acervo pertence simultaneamente a tudo isso.

É neste sentido que podemos dizer que determinados lugares de memória estão contidos em outros lugares de memória e desafiam o nosso entendimento acerca das possíveis tessituras entre macro e micro lugares de memória e de esquecimento, de poder e de resistência.

Seguindo por essa trilha, podemos, por fim, sugerir que o denominado patrimônio material é composto de imaterialidades e que o denominado patrimônio imaterial não sobrevive sem a âncora das materialidades.

\section{REFERÊNCIAS}

BENJAMIN, Walter. Obras escolhidas: Magia e Técnica, Arte e Política. 4a . Edição. São Paulo: Brasiliense, 1984. 253p. 
BRANDI, Cesare. Teória de la restauración. Madri: Alianza Editorial. 1989, 149p.

CALVINO, Italo. As cidades invisíveis. São Paulo: Companhia das Letras, 1999. 152p.

CHOAY, Françoise. A alegoria do patrimônio. Rio de Janeiro, São Paulo: Estação Liberdade: Editora UNESP, 2001.

CURY, Isabelle (org.). Cartas patrimoniais. 2a ed. Ver. Aum. Rio de Janeiro: IPHAN, 2000.

D' AMBRÓSIO, Ubiratan. Da realidade à ação: reflexões sobre a Educação (e) Matemática. São Paulo: Summus/Unicamp, 1988. 115p.

FONSECA, Maria Cecília Londres. O patrimônio em processo. Rio de Janeiro: Editora UFRJ; MinC - IPHAN, 2005.

GEERTZ, Clifford. The interpretation of culture. London: Hutchinson, 1975.

GONÇALVES, José Reginaldo Santos. Os museus e a cidade. In, ABREU, Regina; CHAGAS, Mário. (orgs.) Memória e Patrimônio: ensaios contemporâneos. Rio de Janeiro: DP\&A, 2003.

HALBWACHS, Maurice. A memória coletiva. São Paulo: Centauro, 2004. 197p.

MAUSS, Marcel. Sociologia e Antropologia v.II. São Paulo: Edusp, 1974.

MELLO NETO, João Cabral de. Museu de Tudo e depois. Rio de Janeiro: Nova Fronteira, 1988. 340p.

PIRES, Vladimir Sibylla. Museu-monstro: insumos para uma museologia da monstruosidade. Tese de doutorado defendida no Programa de Pós-graduação em Ciência da Informação do IBCT/UFRJ. Rio de Janeiro: IBCT/UFRJ, 2014. 172p.

RAPOPORT, Amos. The meaning of the built environment. Beverly Hills: Sage Publishings, 1983.

RIO, João do. A alma encantadora das ruas: crônicas. Org. Raúl Antelo. São Paulo: Companhia das Letras, 1997.p377-405. 

sentido em Paraty - Mario Chagas e Claudia Storino

SANT'ANNA, Márcia. Da Cidade Monumento à Cidade Documento - Trajetória de uma norma de preservação de áreas urbanas no Brasil (1937-1990). Dissertação de mestrado apresentada à Faculdade de Arquitetura e Urbanismo da Universidade Federal da Bahia, 1995.

SANTOS, Milton. Pensando o espaço do homem. São Paulo: Edusp, 2004.

SOUZA, Marina Mello e. Paraty: a cidade e as festas. Rio de Janeiro: UFRJ/Tempo Brasileiro, 1994. 662p.

STORINO, Claudia Maria Pinheiro. Paraty: museu e cidade-patrimônio (o lugar de memória do lugar de memória). Dissertação de mestrado defendida no Programa de Pós-graduação em Memória Social - UNIRIO. Rio de Janeiro: UNIRIO, 2008, 183p.

\section{Sites}

http://revistas.ulusofona.pt/index.php/cadernosociom useologia/article/viewFile/366/275.

portal.iphan.gov.br/portal/montarPaginaSecao.do?id=1 2456\&retorno=paginalphan. 